\title{
The year 2020, a milestone in breaking the vicious cycle of poverty and illness in China
}

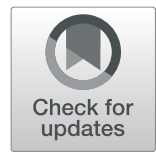

\author{
Yun-Ping Wang ${ }^{1}$ and Xiao-Nong Zhou $2,3,4^{*}$
}

\begin{abstract}
Marking the end of the five-year programme initiated by the Chinese Government to lift more than 70 million people out of poverty, the year 2020 is a milestone. Poverty alleviation has moved strongly forward in China and the major health indicators are now better than the average of all middle- and high-income countries. However, the dual burden of infectious and chronic diseases remains a challenge with respect to achieving the health target in the United Nations 2030 Agenda for sustainable development goals (SDGs). In 2015, about 44\% of the poor population in China were impoverished by illness but already in 2018, multi-sectoral actions delivered by the Health-related Poverty Alleviation programme had reduced the number almost by half. In the past three years 15 million poor people ( $98 \%$ of the poor population) with infectious and chronic diseases had been treated and taken care of thanks to financial support through multiple health insurance schemes and other governmental subsidies. This article discusses the lessons learnt with regard to health-related poverty alleviation in China with special reference to those still remaining impoverished by illness. Consolidation of the achievements reached and provision of basic needs to those still disadvantaged and in poor health will require a major improvement of accessibility to, and affordability of, health services. The next step towards enhanced productivity and better living conditions will involve upgrading of the capacity of health professionals in the poor regions, promotion of coherent efforts in health-related poverty alleviation and rural revitalization measures. As an additional measure, data monitoring and research on health poverty alleviation should be strengthened as they are essential to generate the evidence and knowledge needed to support the move in the direction envisioned by the SDGs, and the new Healthy China 2030 programme.
\end{abstract}

Keywords: Poverty alleviation, Infectious diseases, Poor population, Health insurance, Endemic diseases, China, Healthy China

\section{Background}

Ending poverty in all its forms everywhere is the first goal of the 17 Sustainable Development Goals (SDGs) of the United Nations 2030 Agenda [1]. This goal, promising to leave no one behind [2], recognizes that ending poverty is the greatest of the global challenges ahead [3], since $10 \%$ of the world's population still live at or below USD 1.90 a day (the internationally agreed poverty line). Although this figure is down from $36 \%$ in 1990 to $16 \%$

\footnotetext{
* Correspondence: xiaonongzhou1962@gmail.com

${ }^{2}$ National Institute of Parasitic Diseases at Chinese Center for Diseases Control and Prevention; Chinese Center for Tropical Diseases Research, Shanghai 200025, China

${ }^{3}$ WHO Collaborating Centre for Tropical Diseases; National Center for International Research on Tropical Diseases, Ministry of Science and Technology; Key Laboratory of Parasite and Vector Biology, Ministry of Health, Shanghai 200025, China

Full list of author information is available at the end of the article
}

in 2010 in China [4-6], the goal is still far away. Efforts to reduce poverty in association with poor health due to major communicable afflictions such as HIV/AIDS, tuberculosis, malaria, hepatitis and neglected tropical diseases (NTDs), as well as maternal mortality, preventable deaths of newborns and children less than 5 years old [2], were already part of the Millennium Development Goals (MDGs), which have now been supplanted by the SDGs. Indeed, poverty is the greatest adversary in relation to health in the developing countries and current evidence illustrates that good health is not only an outcome, but an essential component of poverty reduction [7].

Not that long ago, China had the world's biggest poor population, but has made spectacular progress in reducing health-related poverty [8] and became already the first country to meet the MDG targets for reduction of

(C) The Author(s). 2020 Open Access This article is distributed under the terms of the Creative Commons Attribution 4.0 International License (http://creativecommons.org/licenses/by/4.0/), which permits unrestricted use, distribution, and 
the number of poor people by 2015 [9]. Over 700 million people, amounting to $70 \%$ of the world's total poor, have been lifted above China's national poverty line since 1978, the time when the country opened up and started economic reform [10]. As of 2014, China still had 70.2 million people in the rural areas living below the poverty line [8]. This population was identified and selected as target for a programme referred to as the "Decision of the Central Committee of Communist Party of China and the State Council on Winning the Tough Battle against Poverty" [11]. In 2015, the President of China Xi Jinping pronounced that "a well-off society is for all people in China, no one should be left behind over next five years, China will lift all its current 70 million living beneath the poverty line to safety, which is an important step in implementing development agenda after 2015 achieving China's two centenary goals for development" [12]. With this he set in motion the fight against health-related poverty, one of the top priorities of the programme mentioned above. However, it is now clear that the two centenary goals cannot be reached in entirety without successful efforts to alleviate and eventually eradicate extreme poverty [13].

According to the latest official data published by the Chinese Government, the rural poor population has been reduced by 80 million in total, which corresponds to an annual average decline of around 12 million people. Meanwhile, the poverty incidence rate declined at an annual rate of $13.8 \%$ (Fig. 1) receding from $10.2 \%$ in 2012 to $1.7 \%$ in 2018 . By the end of 2019, an estimated $95 \%$ of the poor population around 11.09 million had been lifted out of poverty [12, 14]. Furthermore, the overall health status of the Chinese people has now become better than the average of the middle- and highincome countries in the past 5 years. For instance, from
2015 to 2018, the average life expectancy increased from 76.34 to 77 years, the infant mortality declined from $8.1 \%$ o to $6.1 \%$, the under- 5 mortality rate dropped from $10.7 \%$ to $8.4 \%$ and the maternal mortality rate fell from 20.1 to 18.3 per 100000 [15].

Three basic questions are up-front when looking at available evidence-based data from China:

1. What is the connection between poverty and illness?

2. How can the vicious cycle of poverty and illness be defeated?

3. Which are the major lessons to be learnt from the health-related poverty alleviation programme?

\section{Poverty leads to illness}

Health affects national economic growth because people with disease or disability are likely to be less productive at work, lose their jobs, retire or die prematurely. Naturally, all of these outcomes decrease household earnings and increase the risk of poverty. Hence, the foregone reduction of national income due to illness is considerable in countries where poor health is common. For example, the projected cumulative global loss of economic output due to non-communicable diseases (NCDs) from 2011 to 2030 is estimated at USD 47 trillion, with the joint share of the low and middle income countries (LMICs) amounting to around USD 21.3 trillion (46\%) [16]. In addition, the cost for treatment of major infectious diseases, such as those mentioned above and/or increased microbial resistance to therapeutic drugs incur a financial shortfall for affected individuals and households. Out-of-pocket payments trap poor and near-poor households in a vicious cycle due to large personal expenditures leading to impoverishment and worse health,

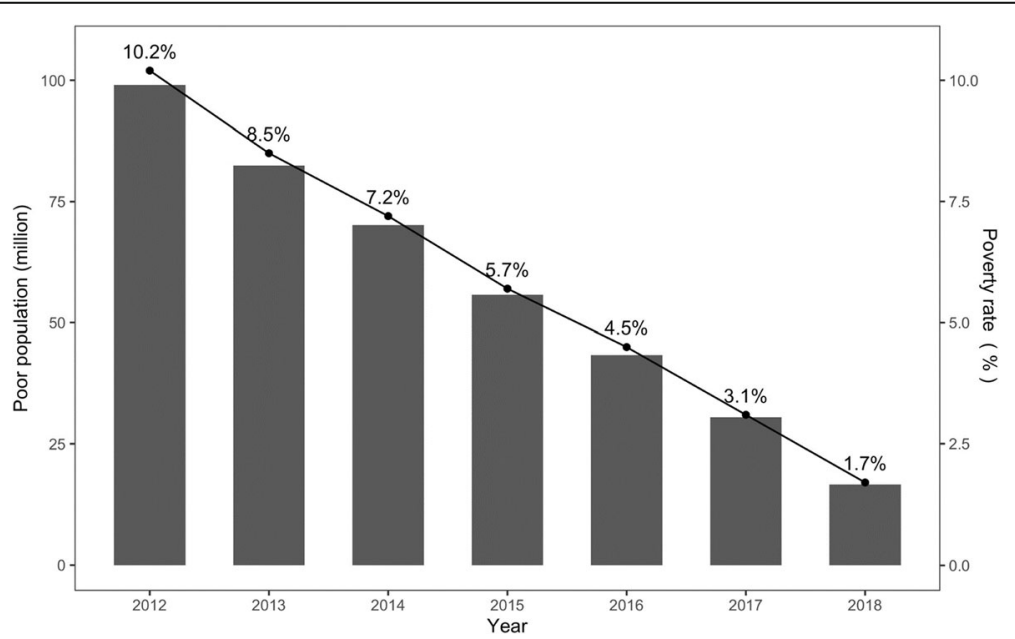

Fig. 1 The progress in China's poverty alleviation programme from 2012 to 2018. (Date source: National Bureau of Statistics, Statistical Bulletin of the National Economic and Social Development, 2012-2018) 
particularly in the LMICs where social health insurance schemes are generally lacking. Besides the NCDs and major infectious diseases, the NTDs constitute a group of diseases in tropical environments closely associated with poverty proliferation [9, 17]. Although many countries have made progress in the elimination of NTDs, an estimated 1.5 billion people in 2016 still require treatment and care due to affliction with one or more NTDs, among them about 400 million (27\%) in low-income countries [4], emphasizing the worldwide presence of poverty and inequality. Every year, a reportedly 100 million people globally are pushed into poverty, often due to illness and pre-existing sickness aggravated by lack of essential health services [18].

As a large proportion of illnesses in the developing countries are entirely avoidable or treatable with existing medicines or interventions, disease burdens in these countries are often due to consequences of poverty, including poor nutrition, indoor air pollution and lack of access to proper sanitation and health education.

Historically, China has spent far too little on health, partly because health has not been seen as a "productive" part of the economy and also because of a previously low national income [19]. One of the lessons learnt was the disastrous collapse of Rural Cooperative Medical Scheme (RCMS), a community-based voluntary medical assistance scheme in the 1980s, which led to more than 800 million rural Chinese losing health care coverage in the following two decades $[20,21]$. Some of the rural households are impoverished and discontent due to increasing medical expenses and long-term health care costs that could not be afforded.

Alerted by several public focus events related to unaffordability of health expenditure, and the outbreak of the severe acute respiratory syndrome (SARS) in 2003, the Chinese Government launched the rural New Cooperative Medical Scheme (NCMS) for all the rural residents and rural Medical Financial Assistance Scheme (MFAS) for the rural poor to cover their health expenditure that year, and implemented a new health care reform in 2009, promising RMB 850 billion (USD 123 billion) over 3 years to provide universal health coverage, strengthened health services delivery and drug supply for its population then amounting to 1.3 billion [21, 22]. Currently, more than $95 \%$ of the Chinese population is covered by social health insurance schemes [23], and the percentage of people who needed, but did not receive, hospital-based treatment due to financial hardship decreased from $29.6 \%$ in 2003 to $17.1 \%$ in 2013 [24]. This ignores those who seek treatment but fall into poverty as a result of expenditure. However, this kind of poverty-related lack of proper care is still a challenge in China and to eliminate infectious diseases among the poor and improve their accessibility and affordability with respect to disease prevention, treatment and rehabilitation services will take more time [25]. For example, the results from three rounds of a national survey of important parasitic diseases showed that with the economic development, the average prevalence rate of soil-transmitted helminthiasis dropped from $59.8 \%$ in 1991 to $19.6 \%$ in 2003, and continued down to $4.8 \%$ in 2013 [9]. Another example is malaria, a disease with high mortality that traps households in poverty in many countries with a high burden of this infection [26-28], where Chinese evidence shows a significant Spearman's rank correlation coefficient correlations between poverty and incidence of malaria $(0.88, P<0.01)$, as well as between poverty and epidemic hemorrhagic fever $(0.89, P<0.01)$ for the years 1990-2018 [15, 29-31] (Fig. 2). Among the poor in China, more than $44 \%$ are still impoverished by illness, such as cancer, childhood leukaemia, congenital heart disease, end-stage renal disease and infectious diseases, tuberculosis and parasitic diseases in particular [33].

\section{Defeating the vicious cycle}

For the national poverty alleviation policy announced by the Chinese Government in 2015, the key measures include: (i) establishing a long-term mechanism for poverty relief and wealth acquisition; (ii) strengthening of infrastructure and basic public services in poor regions; and (iii) support for development of local industries and economy. The programme, identified as a priority in the overall framework to roll back poverty, has a five-area focus: (i) improving access to essential health services covered by health insurance and financial assistance schemes; (ii) strengthening health infrastructure and service delivery capacities in poor and rural regions; (iii) providing educational and training opportunities including attractive recruitment and retaining policies for the health workforce; (iv) promoting infectious and endemic disease elimination; and (v) supporting maternal and child health and nutrition in poor regions. These activities proved effective in responding to health-related poverty and 6.7 million households have been lifted out of the trap of impoverishment due to illness [23].

Success in fighting health-related poverty can be attributed to a two-pronged approach: i) strong political commitment and substantial investment from the government at all levels; and ii) appropriate technical strategies for improving health care and public health for the poor [8]. At the political level, the central government convened a national health conference in Beijing in 2016 to promote "Healthy China 2030", a new domestic, cross-sectoral, long-term strategy to support global health and health-related SDGs with the slogan "Healthy lives and well-being for all" that was also used to continue the efforts combating emergence or re-emergence of infectious diseases. Given the universal and multisectoral nature of health, there is an urgent need to elevate work towards health to a higher level of priority and importance in many national contexts. The "Shanghai Declaration on Promotion of Health in the 2030 Agenda" reinforces good governance at all levels and is 

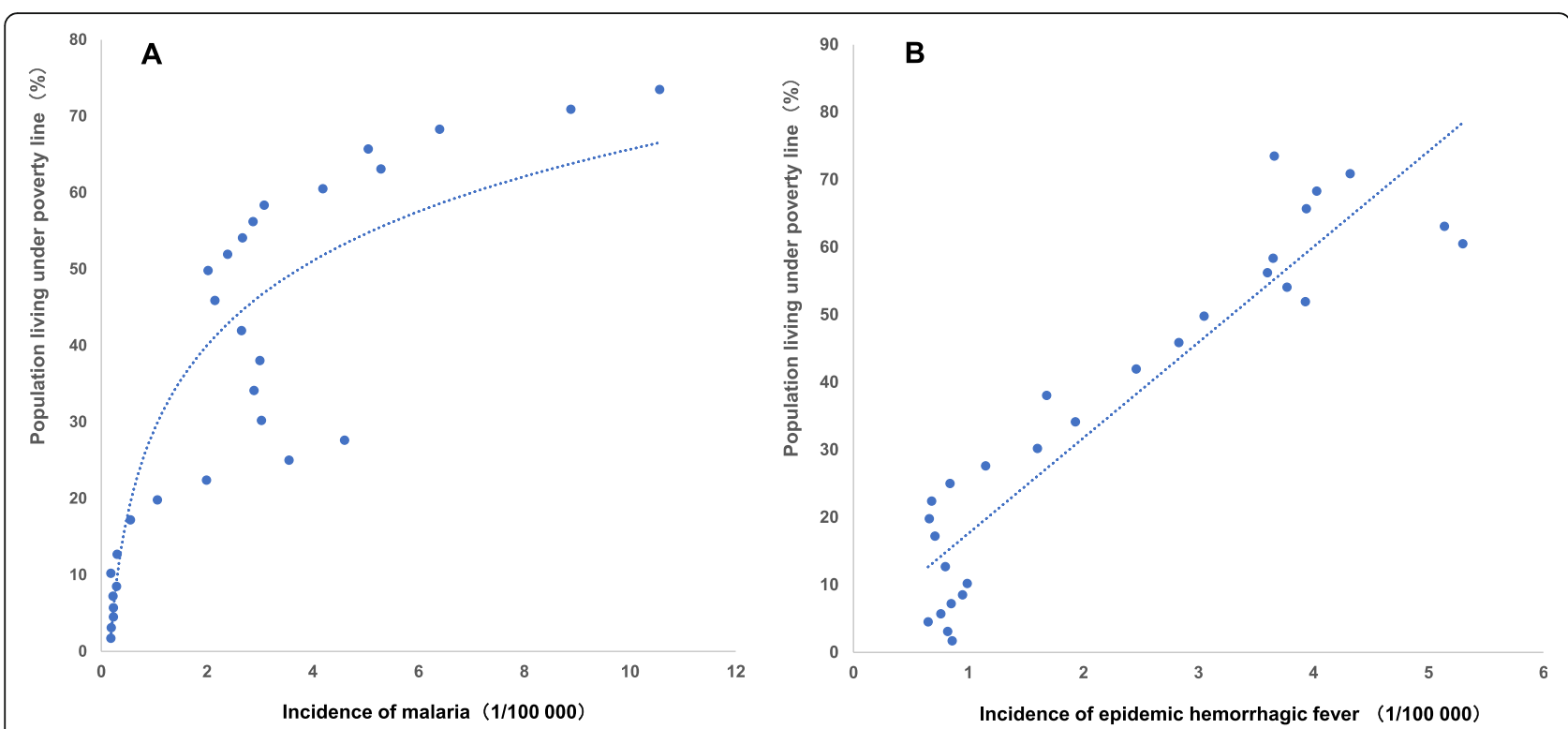

Fig. 2 Poverty incidence and incidence of malaria (a) and epidemic hemorrhagic fever (b) in China (1990-2018) [15]. (a Spearman's rank correlation coefficient of poverty incidence and malaria incidence is $0.88(P<0.01)$. b Spearman's rank correlation coefficient of poverty incidence and epidemic hemorrhagic fever incidence is $0.89(P<0.01)$. Data source: Poverty incidence data is from World Bank database; and the incidence data of malaria \& epidemic hemorrhagic fever is from China Health Statistics Yearbook 2019)

crucial for improving health-related matters [33, 34], which require investment and action at the local, national and also global levels. Thus, health is perceived as a crucial entry-point to achieving the SDGs because of its ability to lift people out of poverty making it central for individual, household and national socioeconomic development. Health is also is a critical component of human capital contributing to employability of people and general economic productivity.

The Government in China has explored ways to make health a multi-department priority and ensure crosssectoral cooperation through a range of mechanisms and institutions. The WHO 2010 Adelaide Statement produced a framework with health promotion as key policy components which has successfully reduced healthrelated poverty [35]. In 2016, the National Health Commission of China, together with other relevant 14 ministries, issued guidelines for health poverty alleviation programme aimed to break the vicious cycle between poverty and illness by 2020 . In 2018, six more concrete actions were proposed to achieve Health-related Poverty Alleviation by 2020 . Those actions included (i) improved medical care insurance for the targeted poverty-stricken population; (ii) provision of treatment and health management services covered by serious illness insurance for the poor with serious chronic diseases (which led to the expansion of the spectrum of serious chronic diseases from 9 to 30 diseases); (iii) implementing prevention and control of communicable and endemic diseases using an integrated strategy in poverty-stricken areas aimed at controlling HIV/AIDS, tuberculosis, echinococcosis, schistosomiasis, Kaschin-Beck disease (an endemic type of osteochondropathy) and Keshan disease (cardiomyopathy caused by a combination of selenium deficiency and a mutated Coxsackie virus); (iv) improving the delivery capacities in poverty-stricken regions at the county, township and village levels; (v) supporting maternal and child health and health promotion in poverty-stricken region; and (vi) strengthening support systems with priorities in policy making, project allocation, funding and social support to reduce poverty in the areas with most poverty (Fig. 3).

At the technical level, the principal approach was to find gaps related to limited or lack of qualified medical resources and to deliver sufficient and quality reliable health services to local populations. For example, by 2015 there were only 3.66 beds per 1000 population, and 1.28 certified medical doctors or assistants per 1000 population in the 832 poverty-stricken counties in China, the numbers of which are much lower than that of the average numbers at national level $[12,36]$. Secondly, precise health-related poverty alleviation approaches were performed at the county, family and individual levels with a focus on the most serious regions, targeted populations, and key diseases, aiming at integrating prevention with treatment by financial assistance through the poverty alleviation programme. Thirdly, detail objectives were identified to ensure 


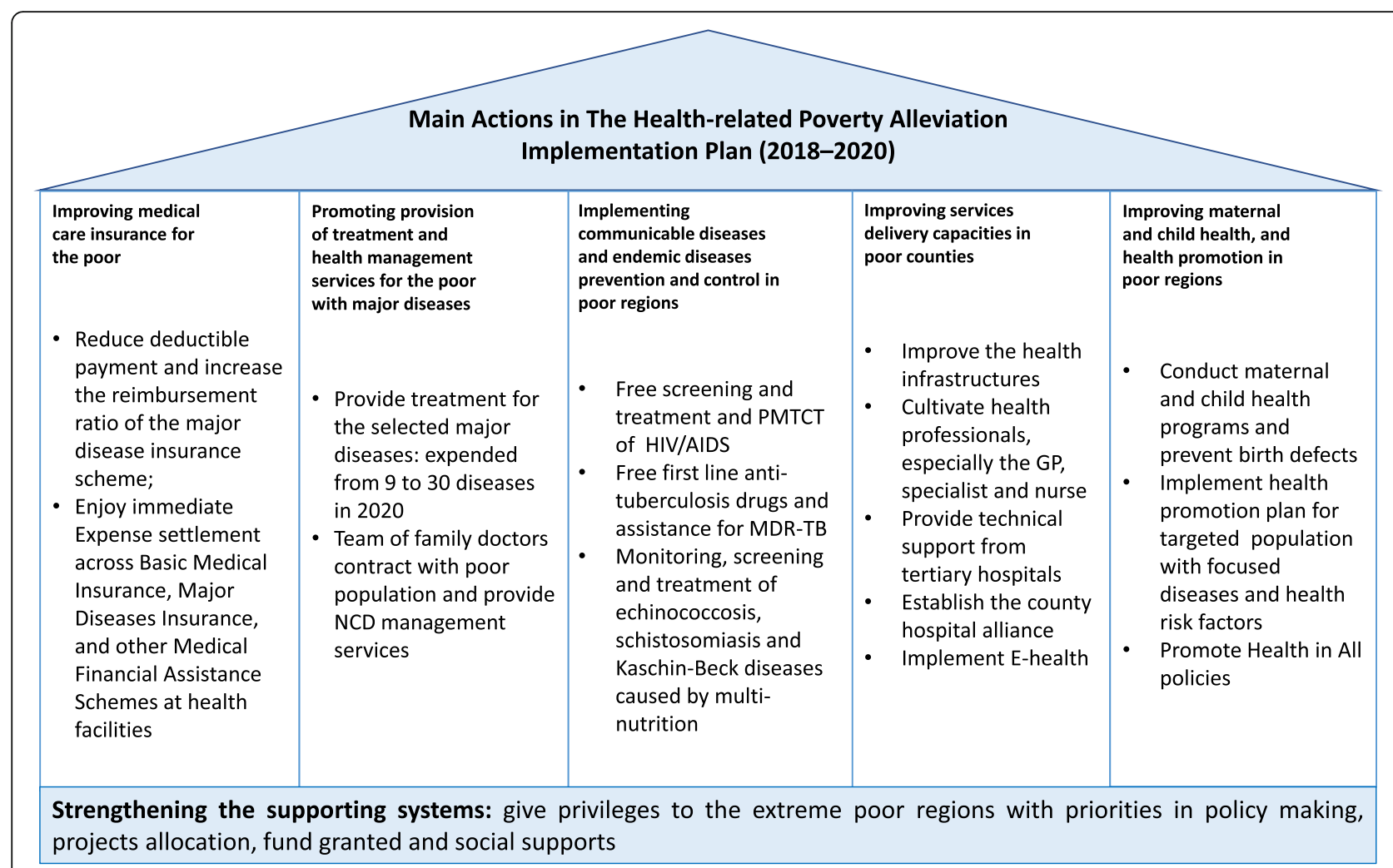

Fig. 3 The diagram of the Main Actions of Health-related Poverty Alleviation Programme in China. (Source: China National Health Commission [36]). NCD: Noncommunicable disease; PMTCT: Prevention of mother-to-child transmission of HIV; MDR-TB: Multidrug-resistant tuberculosis; GP: General Practitioner

provision of primary health care to all povertystricken populations, and also to upgrade the capacity of the medical resources and services delivery to the national average level. Fourthly, the three-pronged approaches were implemented by the following steps: (i) reviewing the epidemic trend and financial burden of the diseases among the poor population through a digital information platform; (ii) classifying the poor populations by disease, treatment service and financial protection needed; and (iii) identifying the most important diseases by population and geographical region by mapping for better targeting of medical care services and financial assistance (Fig. 3). In addition, a three-years implementation plan on health-related poverty alleviation between 2018 and 2020 was implemented by the National Health Commission aiming to prioritize eradication of iodine deficiency, skeletal fluorosis and arsenic poisoning caused by coal burning and upgrade disease control with special reference to Kaschin-Beck and Keshan disease, as well as eliminate schistosomiasis as public health problem and effectively control echinococcosis in western China. Good progress on all these fronts has already been noted in the poverty-stricken areas.

\section{Lessons learnt}

The successful lifting 730 million people out of extreme poverty in the past four decades is mainly due to impressive economic growth and coherent policies that favoured improvements in incomes and livelihoods for the poorest of the poor $[12,36]$. The major activities of the successful poverty alleviation programme can be summarized as follows:

(i) Through investigation and registration of all poor households and individuals, several key diseases with clear diagnoses and treatment pathways adding financial burdens to the stricken households could be selected. Up to 30 major diseases were covered by the targeted assistance package, including childhood leukaemia, congenital heart disease, tumours, end-stage renal disease to mention a few. With respect to chronic diseases in poor patients, e.g., hypertension, diabetes, tuberculosis and severe mental disorders, family doctors were paid to offer systematic health management.

(ii) By combining disease prevention with treatment along the approaches of the Health Poverty Alleviation programme, both the capacity of health services delivery and financial protection could be improved. Preventive and treatment services for HIV/AIDS, multi drug 
resistance tuberculosis, Kaschin-Beck disease, Keshan disease and NTDs including schistosomiasis and echinococcosis were among the diseases covered into the targeted disease treatment and subsidy package. The Chinese Government invested in standardized construction of county and township hospitals and village clinics, promoting tiered and integrated health services delivery, supporting hospital-to-hospital assistance between urban and rural areas and encouraging medical college graduates to work in the rural and remote areas in central and western China. In addition, all registered poor people now enjoy a three-tiered financial protection, namely basic health insurance, major disease insurance and medical financial assistance schemes. To support the poor population, out-ofpocket payments were capped at $10 \%$ of their health expenditure. For some extremely poor households, out-ofpocket health expenditure was completely covered.

(iii) In order to support the development of better health care in the poverty-stricken regions, the Chinese Government established a strict top-town performance evaluation and accountability mechanism with indicators of poverty alleviation and multi-sectoral cooperation to mobilize various social resources for more precise measures. Many provinces have adopted a mechanism of "one strike and you're out". Under this system, a local government's failure to hit poverty alleviation targets cancels out successes against all other performance targets on which it is assessed. Besides fiscal investment, the Government also made important progress in a number of areas identified by researchers as an essential component of poor people's endogenous development capacities. This includes early childhood development and nutrition, universal health coverage, universal access to quality education and cash transfers to poor families, rural infrastructure, especially roads and electrification and progressive taxation. Private sector and non-governmental organizations, and the communities have also been engaged in the poverty alleviation programme.

Health-related poverty alleviation relies strongly on improving food and nutrition, housing, education, employment and other basic living conditions, which have therefore been incorporated into the systematic, national strategies of the different programmes Health-related Poverty Alleviation, Rural Revitalization and Healthy China 2030. The former programme also promotes other parallel actions tackling key obstacles related to poverty reduction, while the Rural Revitalization Strategy aims to facilitate rural socioeconomic, ecological and cultural development in the post-poverty alleviation period to further consolidate achievements and improve the well-being of the rural population, while the Healthy China 2030 programme acts by improving health infrastructure construction and services delivery in poor counties, thereby providing basic public health services, rehabilitation services and financial protection for the poor.

\section{Looking forward}

The implementation of overarching national strategies in a holistic approach with long-term perspective can theoretically cancel out the impact of negative socioeconomic determinants of health and health-related poverty. However, although the programme on Health-related Poverty Alleviation has already made a great positive impact on socioeconomic development in poor regions, resources such as hospitals beds, doctors and auxiliary staff are still seriously lacking in poor counties which have not been able to deliver sufficient qualitatively reliable services to the population making it difficult to achieve the SDGs health targets in the short term [26]. Therefore, medical services and health insurance and other financial protection systems need to be better aligned. According to the World Bank, the key challenges ahead for China include further improved access of health services for those needing them as well as better data monitoring on poverty and health since those still remaining in poverty, such as the elderly and ethnic minorities, demand even stronger efforts than used so far.

In order to strengthen the health status for all, leaving no one behind and thus achieve the goal of improving the situation for all currently living below the poverty line, the following three actions are recommended: (i) strengthening multi-sectional cooperation and investment coordination during the implementation of health-related poverty alleviation anchored in improving the health services delivery capacities of the rural health facilities, the financial protection capacity to lift out the rural poor with follow-up measures to prevent diseases, maintain health and enhance the productivity abilities; (ii) more intensive and robust research conducive to evidence-based information and its dissemination to decision makers, including research on health systems strengthening in the poor regions, cost-effectiveness analysis and social ethics analysis of priority settings for the decision making in health-related poverty alleviation, and (iii) more actively engagement in global health cooperation and development, such as knowledge sharing and capacity building, to learn from global societies in tackling with the extreme poor with serious illness and incapable to work in the long-run, as well as in generating the experience and lessons from China for other developing countries fighting against health-related poverty.

\section{Conclusions}

The year 2020 marks the end of the major, five-year programme on poverty alleviation initiated by the Chinese Government. Huge progress has already been achieved and the results should now be consolidated to promote further advancement towards the SDGs targets. The challenge in the post-poverty alleviation period is to reach the Healthy China 2030 goal of realizing a world without poverty and endemic diseases. This asks for total elimination of healthrelated poverty and requires China to provide more 
assistance to its extremely poor, many of whom struck with serious illnesses, having lost production resources and being in need of long-term health care.

\section{Abbreviations}

China: The People's Republic of China; LMICs: Low and middle income countries; MDGs: Millennium Development Goals; NCDs: Noncommunicable diseases; NTDs: Neglected tropical diseases; SDGs: Sustainable Development Goals; WHO: World Health Organization

\section{Acknowledgements}

We thank anonymous reviewers for providing comments to improve the manuscript.

\section{Authors' contributions}

XNZ and YPW collected the data, identified the species and wrote the first draft; and XNZ guided the English writing and revised the first draft. All authors read and approved the final manuscript

\section{Funding}

This work was supported by the National Science and Technology Project (Grant No. 2018ZX10101002), the National Key Research and Development Program of China (Grant No. 2016YFC1202000), and the National Natural Science Foundation of China (Grant No. 81273192, 81973108).

\section{Availability of data and materials}

Not applicable.

\section{Ethics approval and consent to participate}

Not applicable.

\section{Consent for publication}

Not applicable.

\section{Competing interests}

XNZ is the Editor-in-Chief of the Infectious Diseases of Poverty.

\begin{abstract}
Author details
${ }^{1}$ China National Health Development Research Centre, National Health Commission of China; WHO Collaborating Centre for Health Systems Strengthening, Beijing 100044, China. ${ }^{2}$ National Institute of Parasitic Diseases at Chinese Center for Diseases Control and Prevention; Chinese Center for Tropical Diseases Research, Shanghai 200025, China. ${ }^{3} \mathrm{WHO}$ Collaborating Centre for Tropical Diseases; National Center for International Research on Tropical Diseases, Ministry of Science and Technology; Key Laboratory of Parasite and Vector Biology, Ministry of Health, Shanghai 200025, China. ${ }^{4}$ School of Global Health, Chinese Center for Tropical Diseases Research, Jiatong University School of Medicine, Shanghai 200025, China.
\end{abstract}

Published online: 30 January 2020

\section{References}

1. United Nations. Transforming our World: The 2030 Agenda for Sustainable Development (A/RES/70/1), 2015. https://sustainabledevelopment.un.org/ post2015/transformingourworld. Accessed 27 Dec 1999.

2. World Health Organization. Health in the post-2015 development agenda. Sixty-sixth world health assembly (A66/47). Geneva: WHO; 2013.

3. Collaborators GS. Measuring the health-related sustainable development goals in 188 countries: a baseline analysis from the global burden of disease study 2015. Lancet. 2016;388(10053):1813-50. https://doi.org/10.1016/S0140-6736(16)31467-2.

4. Engels D. Neglected tropical diseases in the sustainable development goals. Lancet. 2016;387(10015):223-4. https://doi.org/10.1016/S0140-6736(16)00043-X.

5. El-Zein A, DeJong J, Fargues P, Salti N, Hanieh A, Lackner H. Who's been left behind? Why sustainable development goals fail the Arab world. Lancet. 2016;388(10040):207-10. https://doi.org/10.1016/S0140-6736(15)01312-4.

6. Lee YS, Oh JY, Min KH, Lee SY, Kang KH, Shim JJ. The association between living below the relative poverty line and the prevalence of chronic obstructive pulmonary disease. J Thorac Dis. 2019;11(2):427-37. https://doi. org/10.21037/jtd.2019.01.40.
7. Annan K. In: Nations U, editor. Poverty biggest enemy of health in developing world, secretary-general tells world health assemblyhttps://www.un.org/press/ en/2001/sgsm7808.doc.htm. Geneva: United Nations; 2001

8. Hotez PJ. Whatever happened to China's neglected tropical diseases? Infect Dis Poverty. 2019;8, 85(1). https://doi.org/10.1186/s40249-019-0598-5.

9. Qian MB, Chen J, Bergquist R, Li ZJ, Li SZ, Xiao N, et al. Neglected tropical diseases in the People's Republic of China: progress towards elimination. Infect Dis Poverty. 2019;8(1):86. https://doi.org/10.1186/s40249-019-0599-4.

10. Wang Y. China's reform and opening-up creates miracle in poverty reduction. People's Daily. http://en.people.cn/n3/2018/1218/c90000-95295 78.html. Accessed 16 Jan 2020

11. The Central Committee of Communist Party of China and the State Council. Decision on Winning the Tough Battle against Poverty. http://www.gov.cn/ xinwen/2015-12/07/content_5020963.htm. Accessed 16 Jan 2020.

12. National Health Commission: the Press Conference on Heath-related Poverty Alleviation. http://www.nhc.gov.cn/xcs/s7847/201909/6a739ff5ecf4 a76be85eb0509497d8d.shtml. 2019.

13. He C, Liu L, Chu Y, Perin J, Dai L, Li X, et al. National and subnational all-cause and cause-specific child mortality in China, 1996-2015: a systematic analysis with implications for the sustainable development goals. Lancet Glob Health. 2017:5(2):e186-e97. https://doi.org/10.1016/S2214-109X(16)30334-5.

14. National Bureau of Statistics of China: Outstanding achievements for poverty alleviation to continuously improve the people's life in 2019. http://house.china.com.cn/home/view/1625037.htm. Accessed 18 Jan 2020.

15. Natinoal Health Commission of China. China Health Statistic Year Book (2015-2019). Beijing: China Union Medical College Press; 2019. WHO and UNICEF. Health in the Post-2015 agenda. Report of the global thematic consultation on health. Geneva: WHO; 2013.

16. King $\mathrm{CH}$, Bertino AM. Asymmetries of poverty: why global burden of disease valuations underestimate the burden of neglected tropical diseases. PLoS Negl Trop Dis. 2008;2(3):e209. https://doi.org/10.1371/journal.pntd.0000209.

17. Azoh BJ. Social sciences research on infectious diseases of poverty: too little and too late? PLoS Negl Trop Dis. 2014;8(6):e2803. https://doi.org/10.1371/ journal.pntd.0002803.

18. TDR. Global report for research on infectious diseases of poverty. Geneva: World Health Organization; 2012

19. Dong $D$, Jiang WX, Long $Q$, Huang F, Zhang $H$, Chen JY, et al. Impact of an innovative tuberculosis financing and payment model on health service utilization by tuberculosis patients in China: do the poor fare better than the rich? Infect Dis Poverty. 2019;8(1):44. https://doi.org/10.1186/s40249-019-0559-z.

20. Ge YF, Shi G, Lei HH. Evaluations and suggestions on health system reform in China. China Dev Rev. 2005:7:1-14.

21. Yip W, Hsiao W, Meng Q, Chen W, Sun X. Realignment of incentives for health-care providers in China. Lancet. 2010;375:1120-30.

22. Chen Z. Launch of the health-care reform plan in China. Lancet. 2009:373:1322-4.

23. Natinoal Health Commission of China. Achievements in deepening the health care reform in the 70th anniversary of the founding of new China. http://www.nhc.gov.cn/tigs/s7847/201909/548c3274c1 be41e2b1d15624c0d1 8337 shtml. 2019. Accessed 30 Dec 2019

24. Center for Health Statistics and Information NHFPC. Analysis report of the fifth national health services survey in China. Beijing: China Union Medical University Press; 2015.

25. Chen S, Guo L, Wang Z, Mao W, Ge Y, Ying X, et al. Current situation and progress toward the 2030 health-related Sustainable Development Goals in China: A systematic analysis. PLoS Med. 2019;16(11):e1002975; https://doi. org/10.1371/journal.pmed.1002975.

26. Ren M. Greater political commitment needed to eliminate malaria. Infect Dis Poverty. 2019;8(1):28. https://doi.org/10.1186/s40249-019-0542-8.

27. Worrall E, Basu S, Hanson K. Is malaria a disease of poverty? A review of the literature. Trop Med Int Health. 2005;10(10):1047-59. https://doi.org/10.1111/ j.1365-3156.2005.01476.x

28. Bi Y, Tong S. Poverty and malaria in the Yunnan province, China. Infect Dis Poverty. 2014;3:32. https://doi.org/10.1186/2049-9957-3-32.

29. Sun L, Zou LX. Spatiotemporal analysis and forecasting model of hemorrhagic fever with renal syndrome in mainland China. Epidemiol Infect. 2018;146(13):1680-8. https://doi.org/10.1017/S0950268818002030.

30. Hu T, Liu YB, Zhang SS, Xia ZG, Zhou SS, Yan J, et al. Shrinking the malaria map in China: measuring the progress of the National Malaria Elimination Programme. Infect Dis Poverty. 2016;5(1):52. https://doi.org/10.1186/s40249-016-0146-5.

31. Chen TM, Zhang SS, Feng J, Xia ZG, Luo CH, Zeng XC, et al. Mobile population dynamics and malaria vulnerability: a modelling study in the 
China-Myanmar border region of Yunnan Province, China. Infect Dis Poverty. 2018;7(1):36. https://doi.org/10.1186/s40249-018-0423-6.

32. China Population and Development Research Cente. Research Report on the development of healthy poverty alleviation in China. Beijing: People's Publishing House, 2018.

33. Watkins DA, Nugent R, Saxenian H, Yamey G, Danforth K, Gonzalez-Pier E, et al. Intersectoral policy priorities for health. In: Rd, Jamison DT, Gelband H, Horton S, Jha P, Laxminarayan R, Mock CN, Nugent R, editors. Disease control priorities: improving health and reducing poverty. Washington (DC): World Bank Group; 2017. http://documents.worldbank.org/curated/en/52 7531512569346552/Disease-control-priorities-improving-health-andreducing-poverty.

34. World Health Organization. Shanghai declaration on promoting health in the 2030 agenda for sustainable development. Health Promot Int. 2017; 32(1):7-8. https://doi.org/10.1093/heapro/daw103.

35. World Health Organization. Adelaide statement on health in all policies: moving towards a shared governance for health and well-being, report from the international meeting on health in all policies, Adelaide 2010. https://www.who.int/social_determinants/publications/countryaction/ adelaide_statement_hiap/en/. Geneva: WHO; 2010

36. National Health Commission of China. National Development and Reform Commssion, Ministry of Finance, National Healthcare Security Administration, The State Council Leading Group Office of Poverty Alleviation and Development. Implementation Plan of Three-year Key Action of Health-related Poverty Alleviation. 2018. http://www.scio.gov. cn/32344/32345/39620/40079/xgzc40085/Document/1650486/1650486.htm. Accessed $16 \operatorname{Jan} 2018$

Ready to submit your research? Choose BMC and benefit from:

- fast, convenient online submission

- thorough peer review by experienced researchers in your field

- rapid publication on acceptance

- support for research data, including large and complex data types

- gold Open Access which fosters wider collaboration and increased citations

- maximum visibility for your research: over $100 \mathrm{M}$ website views per year

At $\mathrm{BMC}$, research is always in progress.

Learn more biomedcentral.com/submissions 